\title{
Effect of the video-assisted planned programme on breast self-examination among married women
}

\author{
Sarma Bitumani, Bhuyan Hemeswari ${ }^{2}$, Das Krishna ${ }^{3}$
}

Received on 15th November 2019; editorial approval on $20^{\text {th }}$ June 2020

\begin{abstract}
Introduction: Early detection of breast cancer plays an important role in decreasing its morbidity and mortality. This paper aims to assess the level of knowledge on breast self-examination (BSE), the effect of VAPTP (Video-assisted planned programme) and to find out the association between pre-test knowledge on BSE among married women. Materials and methods: An evaluative research approach and one group pre-test and post-test pre-experimental design were adopted. Multi-stage random sampling technique was used to select a sample of 116 married women who fulfilled the inclusion criteria. A self-administered structured questionnaire was used to collect the demographic variables and to assess the knowledge of BSE. In the study the independent variable was VAPTP and the dependent variable was the effect of VAPTP. Results: In the pre-test, 98.2\% had moderate levels of knowledge on BSE and $89.66 \%$ had adequate, $10.34 \%$ had moderate levels of knowledge in post-test. The finding also shows that there is no significant association between the pre-test knowledge scores with the selected demographic variables at 0.5 levels of significance. Conclusion: It can be asserted that BSE is an effective way to improve the knowledge of married women. So, the health worker should conduct screening programme and health camp regarding BSE as a preventive measure of breast cancer in the society. This will be helpful to reduce stigma and attitude of society towards breast cancer and BSE.
\end{abstract}

Keywords: Breast cancer; knowledge; preventive measure.

\section{INTRODUCTION}

Breast cancer is a common cancer in women both in the developed and developing world. The incidence of breast cancer is rising in every country of the world especially in developing countries such as India due to increasing life expectancy, increase urbanization and adoption of western lifestyles. In India, it accounts for the second most common cancer in Women. ${ }^{1}$

The incidence of breast cancer increases with age, doubling about every 10 years until the menopause. BSE is a technique that people can try at home. The signs of the disease are the presence of lumps or thickening in the breast or armpit, discharge from the nipple, discolouration or change in the texture of the skin overlying the breast and change in the direction of the nipple. ${ }^{2}$

Reducing the incidence of advanced breast cancer by having knowledge of BSE and coupled with additional influences could promote successful ageing for elderly women. ${ }^{3}$

According to the consolidated report of the PBCRs: 20012004 - in India breast cancer incidence rate in Chennai 29.3\%, Delhi 29.2\%, Mumbai 27.5\% and Bangalore $27.5 \%$ had higher age-adjusted rate than those PBCRs (population-based cancer registers) of the North-East in Aizawl 26.0\% and Kamrup urban $24.3 \%$. $^{4}$

\author{
Address for Correspondence: \\ ${ }^{1}$ Clinical instructor \\ MMC Hospital, Panbazar, Guwahati, Assam, India \\ Email: bitumoni20@gmail.com \\ Mobile: +918638542790 \\ ${ }^{2}$ Associate professor (Corresponding author) \\ Email: hemamunukunu@gmail.com \\ Mobile: +919435115962 \\ ${ }^{3}$ Retired Professor \\ Regional College of Nursing, Guwahati, Assam, India
}

Cite this article as: Sarma Bitumani, Bhuyan Hemeswari, Das Krishna. Effect of the video-assisted planned programme on breast self-examination among married women. Int J Health Res Medico Leg Prae 2020 July;6(2):39-42. DOI 10.31741/ ijhrmlp.v6.i2.2020.8 
BSE functions as effective preventive health behaviour. Only $19 \%$ to $40 \%$ of women practice BSE every month, and there is no strong evidence that women who practice monthly BSE perform the procedure correctly. Women need to be given the facts about breast cancer and information about early detection methods and also need to be taught BSE in such a way that they feel confident in their BSE skills. ${ }^{5}$

BSE is an inexpensive, risk-free method to detect cancer. When lumps are discovered at an early stage, patients have a better chance for long term survival. For women in their $20 \mathrm{~s}$ and $30 \mathrm{~s}$, it is recommended that clinical breast examination must be a part of their periodic health examination. Beginning in their 20s women should be told about the benefits and limitations of BSE. ${ }^{6}$

BSE enables a woman or girl to detect changes in her breasts. Breast Self-Examination should be performed once every month on the women of 20 years of age and continue each month throughout a woman's lifetime. It is preferable to do Breast Self-Examination for menstruating women on the same day of each month 7-10 days after the first day of the period. For menopause and pregnant women, it is to choose the same day of every month. This method of self-examination is useful in the early detection of breast cancer. ${ }^{7}$

BSE is a check-up that a woman does by herself at home to look for changes or problems affecting the breast tissue. $\mathrm{BSE}$ is still recommended as a general approach to increase breast health awareness and thus potentially allow for early detection of any anomalies because it is free, painless and easy to practice. $^{8}$

Cities in Assam have a surprisingly high number of breast cancers occurring in younger women, compared to rest of India. Breast cancer is more common in the younger age group and $68.8 \%$ of all women suffering from Breast cancer in Guwahati are below 50 years of age. A significant number of patients are below the age of 30 years. ${ }^{9}$

The investigator feels that Breast Self-Examination is an important part of female health care. It helps them to learn how their breasts normally feel so that if they find any abnormality they should know whether it is something to discuss with their health care provider. Moreover, the investigator as a community health nurse has observed that the women have less knowledge regarding BSE. Hence, the investigator has undertaken the responsibility of providing a comprehensive, non-judgemental educational package in the form of a video show to the married women on BSE to enable them to be prepared to do the self-breast examination.

\section{MATERIALSAND METHODS}

An evaluative approach with one group pre-test, the posttest pre-experimental research design was used. The study was conducted selected villages in Hajo Block Primary Health Centre, Kamrup (R), Assam. The target population for the present study was Married women of 18 to 45 years age who are residing in selected villages. Multi-stage random sampling technique was used.10\% was selected for study from the total number of married women of 18 to 45 years. The sample size was 116 .

Structured knowledge questionnaire tool was adopted. The tools consisted of three sections. Section 1- It contains demographic variables: Age, Religion, Education, Number of children, Occupation, Per capita family income per month and Source of information etc.

Sections 2-This part contains knowledge questionnaire on breast self-examination. Questions related to knowledge consists of 20 multiple choices items and having only one correct answer. The total score of knowledge questionnaire is 20 . The total score is divided into three parts: Inadequate $=$ $(<5)$ below $25^{\text {th }}$ percentile; Moderate $=(5-15) 25^{\text {th }}-75^{\text {th }}$ percentile and Adequate $=(>15)$ above $75^{\text {th }}$ percentile

Section 3- The Video Assisted Planned Teaching Programme (Assamese language) was a systematic and organized compact disc prepared by the investigator using the advance technologies of the audio and visual media to provide information to the married women in the aspects of BSE.

Reliability was checked through Karl Pearson's correlation Coefficient formula with the split-half method and " $r$ " value was 0.716 .

The data was collected after getting informed consent from the participants and concerned authorities. Pre-test and VAPTP were done on the same day of data collection. With seven days, gap post-test was done to the same subject by using the same questionnaire.

\section{RESULTS}

The findings were analyzed using descriptive and inferential statistics. Majority of sample about $47(40.5 \%)$ were in the age group 26-35 years, most of the samples $98(84.5 \%)$ belongs to Hindu religion $39(33.6 \%)$ samples had middle school passed, most of the women were housewives $67.2 \%$, maximum married women $40.5 \%$ were $<$ Rs. 5000 per month per capita income; $36.2 \%$ women had two children, $55.2 \%$ got the information from the health personal.

In pre-test minimum score is 4.0 and the maximum score is 16.0 and out of 116 subjects $1(0.90 \%)$ have inadequate knowledge, $114(98.2 \%)$ have moderate and $1(0.90 \%)$ have adequate knowledge.

In post-test minimum score is 13.0 and the maximum score is 20.0 . And out of 116 subjects, $12(10.34 \%)$ have moderate knowledge and 104(89.66\%) have adequate knowledge and none of the subjects has inadequate knowledge. The mean post-test knowledge score (17.46) is higher than the mean pre-test knowledge score (10.99). The standard deviation of the pre-test is 2.25 and post-test is 1.44 . The median posttest knowledge score is higher than the median pre-test knowledge score as shown in Table 1.

The findings of this study revealed that the mean post-test score was higher than the mean pre-test score. The calculated " $t$ " value was greater than the table value of $p<0.000$ as shown in Table 2. Hence it is concluded that there was a 
Table 1 Pre-test and post-test knowledge levels of the subjects regarding breast self-examination

\begin{tabular}{|l|l|l|l|l|l|l|l|l|}
\hline Knowledge level & Mini & Maxi & Median & Mean & Stand dev. & \multicolumn{2}{|l|}{ Percentage (\%) } \\
\cline { 5 - 9 } & & & & & & & & \\
\hline Pre-test & 4 & 16 & 11 & 10.99 & 2.25 & 0.90 & 98.2 & 0.90 \\
\hline Post -test & 13 & 20 & 18 & 17.46 & 1.44 & 0.00 & 10.34 & 89.66 \\
\hline
\end{tabular}

\section{$\mathrm{n}: 116$}

significant gained knowledge through the video-assisted planned teaching programme.

There was no significant association between the pre-test knowledge scores with selected demographic variables, i.e., age, religion, occupation, education, per capita family income per month, number of children and source of information.

Table 2 Pre-test and post-test mean knowledge score of married women regarding breast self-examination

\begin{tabular}{|l|c|c|c|c|c|}
\hline Knowledge scores & Mean & Std. Dev. & df & t & p-value \\
\hline Pre-test & 10.99 & 2.45 & 115 & 25.783 & $0.000^{*}$ \\
\cline { 1 - 4 } Post-test & 17.46 & 1.44 & & & \\
\hline
\end{tabular}

*Statistically Significant, n: 116

\section{DISCUSSION}

In the present study, findings showed that $0.9 \%$ had adequate knowledge in pre-test followed by $98.2 \%$ had moderate knowledge and $0.9 \%$ had inadequate knowledge of BSE. In post-test. $89.66 \%$ had adequate knowledge and $10.34 \%$ had moderate knowledge. In pre-test mean was 10.99 and the post-test mean was 17.46. Similar findings also have been reported by Shalini et al., ${ }^{10}$ who investigated on Awareness and impact of education on BSE among college going girls. The study identified that $72.5 \%$ of students had average knowledge of BSE in pre-test and post-test $15 \%$ of student's average knowledge on BSE. 5\% of students had good knowledge of pre-test and post-test $85 \%$ of students had good knowledge on BSE. In pre-test mean was 27 and the post-test mean was 50 .

The findings of the present study state that the pre-test knowledge means the score was 10.99 and the post-test mean score was 17.46 , which indicate that post-test value is higher than the mean pre-test value. This shows that married women gained knowledge through the video-assisted planned teaching programme. Similar findings were observed by Molly $\mathrm{J}$ et al. ${ }^{11}$ they found that the mean post-test knowledge score of the women was 7.6 and the mean post-test knowledge was 24.9. Which indicate that mean post-test value is higher than the mean pre-test value. The practice of skill in women regarding BSE revealed that the pre-test means skill score 0.7 , and the post-test skill score was 12.4. This indicates the effectiveness of the Video assisted teaching programmes conducted for Married women.

In this study, there was no association between the demographic variables (age, religion, education, number of children, occupation, per capita family income per month and source of information) and pre-test knowledge scores of Married Women regarding BSE. The present study is also supported by Molly J et al., ${ }^{11}$ where they revealed that there is an association between knowledge and selected baseline variables like age, education, and income was computed by using Pearson's product-moment correlation test and found there was no significant relationship between the pre-test knowledge score of Mahila Mandal women. The present study is also supported by Salomy C, ${ }^{12}$ who conducted a study on knowledge of early detection of breast cancer among school teachers. the study revealed that calculated chi-square values were less than the table value for all the variables like age, the number of children, a previous source of information. Table value 5.99, 3.84; $\mathrm{P}<0.05$. Hence, it is inferred that there was no association between the pre-test knowledge score and the selected baseline characteristics.

\section{CONCLUSION}

The present study showed that the knowledge of BSE among married was very less. The video-assisted planned teaching programme on BSE carried out in the study. It was found to be effective in improving the knowledge of married women as evidenced by the significant difference between the pretest and post-test knowledge score. So, the health personnel should intensify health education on knowledge of BSE and should take initiative to improve women's practice of BSE.

Limitation: The study was limited to married women of 1845 years age group.

Recommendation: The same type of study can be conducted on a larger sample for generalization. 
Ethical clearance: Taken.

Conflicts of interest: None.

Source of funding: None.

\section{REFERENCES}

1. WHO. Breast cancer: prevention and control. [Online]. 2018 [cited 2020 Jan 20]; Available from: URL:https:/ /www.who.int/cancer/detection/breastcancer/en/

2. Dowarah BP. Physiotherapy services and its impact on the quality of life in breast cancer patients: review in Assam. Indian journal of physical therapy 2015 January-June;3(1):5-9.

3. Evans KD. Knowledge of breast self-examination and other determinants relationship on the self-rated health status of elderly women. PhD Thesis. Ohio: state university; 2004.

4. ICMR. National Cancer Registry Programme. Bangalore: ICMR; 2006. [cited 2020 Jan 15]; Available from: URL:https:/www.ncdirindia.org/All_Reports/ PBCR_2001_04/PBCR_2001_04.pdf

5. Coleman EA. Practice and effectiveness of breast selfexamination: a selective review of the literature (19771989). J Cancer Educ 1991;6(2):83-92.

6. Sandra M Nettina MSN, APRN, BC, ANP. Lippincott manual of nursing practice. $9^{\text {th }}$ ed. Mumbai: Wolters Kluwer (India) Pvt. Ltd; 2010. p. 886.
7. Arlene L, Suzanne E. Luckmann's medical-surgical book. Philadelphia: WB Saundersl; 1996.

8. Oladimeji1 KE, Tsoka-Gwegweni JM, Igbodekwe FC, Twomey M, Balarabe HS, Akolo C, et al. Knowledge and beliefs of breast self-examination and breast cancer among market women in Ibadan, South West, Nigeria. PLOS ONE 2015 November 25;10(11):1-11.

9. Breast cancer in India. Statistics of breast cancer in Kolkata and Guwahati. [online]. cited 2020 Jan 15]; Available from: URL:https:// www.breastcancerindia.net/statistics/stat_kolkata.html

10. Shalini, Varghese D, Nayak M. Awareness and impact of education on breast self-examination among college going girls. Indian journal of palliative care 2011;17(2):150-54.

11. Molly John, Mercy PJ. Effectiveness of a structured teaching programme on knowledge of breast cancer and skill of BSE: a quasi-experimental study in rural women. International journal of community medicine and public health 2016 (Oct);3(10):2940-43.

12. Salomy C. Effectiveness of planned teaching programme on knowledge of early detection of breast cancer among school teachers. IOSR Journal of Nursing and Health Science 2016 (SepOct);5(5):49-54. 